\title{
ANALISIS MINAT BELAJAR SISWA SMP DENGAN MENGGUNAKAN VBA EXCEL PADA MATERI KPK DAN FPB
}

\author{
Yeti Jumiati ${ }^{1}$, Arpin Chronika Saida Manalu ${ }^{2}$, Siti Chotimah ${ }^{3}$ \\ 1,2,3 IKIP Siliwangi, Jl. Terusan Jendral Sudirman, Cimahi Tengah, Kota Cimahi, Jawa Barat \\ yetiaja890@gmail.com
}

\begin{abstract}
This study was conducted to analyze the learning interest of class VII Junior High School students in mathematics learning KPK and FPB byusing indicators of learning interest namely feeling happy, student interest, study involvement, diligent in learning and doing mathematical assignmens, diligent and learning discipline in learning. Research methods for analysis using descriptive qualitative methods, with the instrument used ini the form of quaestionnaires containing positive and negative statements to analyze student's interest inlearning mathematics. Sampel subjects in the study were seventh grade SMP IT Daarul Fikri Bandung totaling 22 people. The result obtained from the study that the interest in learning mathematics assisted by VBA Excl on the material of KPK and FPB is good.
\end{abstract}

Keywords: Analysis of Student Learning Interest, VBA Excel

\begin{abstract}
Abstrak
Penelitian ini bertujuan untuk menganalisis minat belajar siswa VII SMP dalam belajar matematika pada materi KPK dan FPB berbantuan aplikasi VBA Excel dengan menggunakan 5 indikator minat belajar yaitu perasaan senang, ketertarikan siswa, keterlibatan siswa, rajin dan semangat dalam mengerjakan tugas, dan tekun dan disiplin dalam belajar. Metode penelitian untuk analisis menggunakan metode kualitatif deskriptif, dengan instrumen yang digunakan berupa pemberian angket yang berisi pernyataan positif dan negatif untuk menganalisis minat belajar siswa dalam pembelajaran matematika.Subjek sampel pada penelitian adalah kelas VII SMP IT Daarul Fikri Bandung yang berjumlah 22 orang. Hasil yang didapatkan dari penelitian bahwa minat belajar siswa pada pembelajaran matematika berbantuan VBA Excel pada materi KPK dan FPB adalah baik.
\end{abstract}

Kata kunci: Analisis minat belajar, VBA Excel

Pendidikan adalah suatu usaha sadar dan terencana untuk mewujudkan suasana belajar dan proses pembelajaran agar peserta didik secara aktif mengembangan potensi dirinya untuk memiliki kekuatan spiritual, keagamaan, pengendalian diri, kepribadian, kecerdasan, akhlak mulia serta keterampilan yang diperlukan dirinya, masyarakat, bangsa dan Negara. Sejalan dengan pendapat (Chotimah, Sari, \& Zhanty, 2019), bahwa pendidikan adalah andalan bangsa untuk mempersiapkan sumber daya manusia mengahadapi tantangan zaman.

Perkembangan teknologi dan ilmu pengetahuan yang semakin pesat telah mempengaruhi berbagai aspek kehidupan manusia secara signifikan dalam bidang pendidikan. Pendidikan adalah alat untuk meningkatkan kehidupan manusia dalam taraf yang lebih baik untuk masa yang akan datang. Matematika sebagai salah satu mata pelajaran dasar pada setiap jenjang pendidikan formal yang memegang peranan penting dalam dunia pendidikan dan kehidupan manusia. Matematika sangat perlu diberikan kepada peserta didik mulai dari jenjang sekolah dasar untuk membekali kemampuan berfikir logis, sistematis, kritis dan kreatif, dimana kompetensi tersebut sangat dibutuhkan untuk menghadapi 
masa depan yang penuh persaingan.

Sejalan dengan pendapat (Lestari, 2015), bahwa untuk bertahan hidup pada keadaan yang selalu berubah, tidak pasti dan kompetitif diperlukan kompetensi berpikir logis, sistematis, kritis dan kreatif. Oleh karenanya minat belajar matematika harus ditingkatkan dan memerlukan perhatian khusus mengingat sangat penting untuk masa yang akan datang. Menurut (Gusniwati, 2015), bahwa yang menjadi faktor penting yang mempengaruhi penguasaan konsep matematika adalah minat belajar. Minat erat kaitannya dengan belajar dan belajar tanpa minat akan membuat pembelajaran jadi membosankan.

Minat adalah perasaan suka seseorang terhadap suatu hal, sejalan dengan pendapat (Flora Siagian, 2015), bahwa minat adalah ketertarikan yang timbul dari seseorang pada suatu kegiatan. Jadi minat belajar adalah persaan suka seseorang terhadap suatu kegiatan pembelajaran tanpa adanya paksaan dari luar, tetapi pihak luar dapat menjadi motivasi dalam kegiatan pembelajaran. Menurut pendapat (Rojabiyah \& Setiawan, 2015), minat belajar adalah rasa suka yang timbul dari diri seseorang terhadap kegiatan belajar dengan tidak dipaksa oleh pihak luar.

Berdasarkan uraian di atas minat dapat mendorong berlangsungnya keikutsertaan seseorang dalam kegiatan. Sehingga minat belajar dapat mempengaruhi terhadap hasil belajar seseorang. Proses kegiatan belajar akan bermakna apabila disertai dengan minat. Oleh karena itu seorang pendidik harus membangkitkan minat siswa agar pembelajaran yang diberikan mudah dimengerti.

Minat belajar peserta didik khususnya dalam belajar matematika dapat dilakukan dengan cara apapun, diantaranya adalah menggunakan metode sebagaimana pendapat (Rohaeti \& Purwasih, 2018), menggunakan metode yang efektif agar tercapai tujuan belajar. Dan dengan cara menggunakan media pembelajaran yang menarik sehingga minat peserta didik bertambah dan aktif selama pembelajaran. Menurut (Nurfauziah \& Fitriani, 2019), bahwa pembelajaran berbantuan media VBA Excel merupakan penerapan pembelajaran inovatif yang dapat membuat siswa aktif dalam kegiatan pembelajaran. Dan menurut, VBA Excel aplikasi yang dirancang agar siswa menjadi lebih aktif, dan Microsoft Excel dapat diakses oleh siapa saja yang menggunakan komputer.

Visual Basic Aplication (VBA) adalah bahasa program yang diterapkan dalam aplikasi Excel, yang berfungsi untuk memudahkan pengerjaan, menghemat waktu dan mengoptimasikan jika terjadi kesalahan (Rohaeti E.E, Bernard M, Chotimah, 2018). Selain dapat digunakan sebagai alat bantu dalam proses belajar mengajar khususnya matematika karena memanfaatkan Microsoft Excel dalam pengolahan angka.

Berdasarkan wawancara langsung yang dilakukan peneliti dengan guru mata pelajaran matematika di salah satu SMP swasta di Cimahi, bahwa selama ini pembelajaran matematika belum pernah menggunakan media pembelajaran seperti VBA Excel, oleh karena itu peneliti sangat tertarik untuk mengadakan penelitian pada siswa SMP terhadap minat belajar matematika dengan menggunakan VBA Excel ini. Peneliti akan menggunakan media VBA Excel dalam materi KPK dan FPB. 
Media pembelajaran yang digunakan peneliti ini VBA Excel karena mudah untuk diakses semua siswa, dan perangkat ini terdapat banyak fungsi matematika, dan perangkat ini juga menyediakan banyak gambar. Pada penelitian ini VBA Excel diaplikasikan pada materi KPK dan FPB yang memuat banyak angka yang dapat disajikan dengan menarik, sehingga memotivasi siswa terhadap minat belajar matematika. Berdasarkan latar belakang di atas peneliti akan mengadakan penelitian dengan judul “Analisis Minat Belajar Siswa SMP Menggunakan VBA Excel pada Materi KPK dan FPB.”

\section{METODE}

Metode yang digunakan pada penelitian ini adalah kualitatif deskriptif. Menurut Abdurrahman (Adni, Puji, \& Rohaeti, 2018), penelitian deskriptif bertujuan agar sifat-sifat, individu, gejala atau keadaan atau kelompok dapat digambarkan secara tepat. Sedangkan kulaitatif menurut Meleong (Adni et al., 2018), bahwa penelitian kualitatif sebagai prosedur untukmenghasilkan data deskriptif berupa kata-kata. Subjek sampel dari penelitian adalah siswa kelas VII di SMP IT Daarul Fikri Bandung. Indikator yang digunakan adalah indikator menurut (Hendriana, Rohaeti, \& Sumarmo, 2017), yaitu indikator perasaan senang, ketertarikan siswa, keterlibatan siswa, rajin dalam belajar dan mengerjakan tugas matematika, tekun dan disiplin dalam belajar dan memiliki jadwal belajar.

Rumus persantase yang digunakan adalah Skala Likert untuk menganalisis minat belajar siswa dengan perhitungan rata-rata mengacu pada pencapaian minat belajar. Dengan menggunakan instrument berupa angket yang terdiri dari 20 pernyataan positif dan negatif, dengan menggunakan 4 jawaban yaitu Sangat Setuju, Setuju, Tidak Setuju, dan Sangat Tidak Setuju.

\section{Tabel. 1}

Point Skala Sikap Minat Belajar

\begin{tabular}{l|c|c}
\hline \multicolumn{1}{c}{ Respon } & \multicolumn{2}{c}{ Pernyataan } \\
\hline Sangat Setuju (SS) & 4 & 1 \\
\hline Setuju (S) & 3 & 2 \\
\hline Tidak Setuju & 2 & 3 \\
\hline Sangat Tidak Setuju (STS) & 1 & 4 \\
\hline
\end{tabular}

Data penelititan menggunakan Microsoft Excel dengan rumus persentase menurut Sudijono, yaitu:

Keterangan:

$$
P=\frac{f}{n} \times 100 \%
$$

$\mathrm{P}=$ Persentase jawaban

$\mathrm{f}=$ frekuensi jawaban

$\mathrm{n}=$ banyaknya responden 
Kategori pencapaian nilai menurut Sudijono (Rojabiyah \& Setiawan, 2015)

Tabel. 2

Interprestasi nilai (\%)

\begin{tabular}{c|c}
\hline $\begin{array}{c}\text { Persentase skor } \\
\text { minat }\end{array}$ & Kriteria \\
\hline $0 \%-20 \%$ & Sangat tidak baik \\
\hline $21 \%-40 \%$ & Kurang baik \\
\hline $41 \%-60 \%$ & Cukup baik \\
\hline $61 \%-80 \%$ & Baik \\
\hline $81 \%-100 \%$ & Sangat Baik \\
\hline
\end{tabular}

Tabel. 3

Pernyataan Positif Dan Negatif Skala Sikap Minat Belajar

\begin{tabular}{|c|c|c|c|c|c|}
\hline \multirow[t]{2}{*}{ No. } & \multirow{2}{*}{ Pernyataan } & \multicolumn{4}{|c|}{ Respon } \\
\hline & & SS & $\mathrm{S}$ & $\mathrm{TS}$ & STS \\
\hline A. & Indikator: Perasaan senang & & & & \\
\hline 1. & Matematika adalah pelajaran yang menyenangkan $(+)$ & & & & \\
\hline 2. & $\begin{array}{l}\begin{array}{l}\text { Materi KPK dan FPB menggunakan VBA Excel sangat } \\
\text { menyenangkan }(+)\end{array} \\
\end{array}$ & & & & \\
\hline 3. & Menggunakan VBA suasana kelas menyenangkan $(+)$ & & & & \\
\hline 4. & Saya tidak mengerti materi yang disampaikan oleh guru (-) & & & & \\
\hline 5. & Materi matematika menggunakan VBA sulit dipahami (-) & & & & \\
\hline B. & Indikator: Ketertarikan siswa & & & & \\
\hline 6. & Saya bersemangat mengerjakan soal matematika $(+)$ & & & & \\
\hline 7. & VBA Excel adalah hal yang baru bagi saya (+) & & & & \\
\hline 8. & Guru terlalu cepat menjelaskan pelajaran (-) & & & & \\
\hline 9. & Saya kurang fokus mengerjakan materi dengan VBA (-) & & & & \\
\hline 10. & Saya tidak tertarik menggunakan VBA (-) & & & & \\
\hline C. & Indikator: Keterlibatan siswa & & & & \\
\hline 11. & Saya senang berdiskusi ketika kesulitan mengerjakan soal (+) & & & & \\
\hline 12. & Saya bertanya kepada guru ketika kurang paham $(+)$ & & & & \\
\hline 13. & Saya tidak menyukai diskusi kelompok (-) & & & & \\
\hline $\mathbf{D}$ & Indikator: Rajin dalam belajar dan mengerjakan tugas & & & & \\
\hline 14. & VBA merupakan pembelajaran yang inovatif (+) & & & & \\
\hline 15. & Saya malas membuat catatan pelajaran matematika (-) & & & & \\
\hline 16. & Kalau tidak mengerti saya melihat pekerjaan teman (-) & & & & \\
\hline 17. & Materi yang disampaikan kurang jelas (-) & & & & \\
\hline $\mathbf{E}$ & Indikator: Tekun dan disiplin dalam belajar & & & & \\
\hline 18. & Saya sangat senang apabila diberikan tugas rumah $(+)$ & & & & \\
\hline 19. & Saya berusaha mengerjakan soal matematika meskipun rumit $(+)$ & & & & \\
\hline 20. & Saya merasa gelisah ketika diberi soal matematika (-) & & & & \\
\hline
\end{tabular}




\section{HASIL}

Langkah awal dari penelitian ini adalah mengumpulkan data skala sikap minat belajar siswa setelah diberikan materi KPK dan FPB menggunakan aplikasi VBA Excel. Kegiatan yang dilakukan selama pembelajaran sebagai berikut:

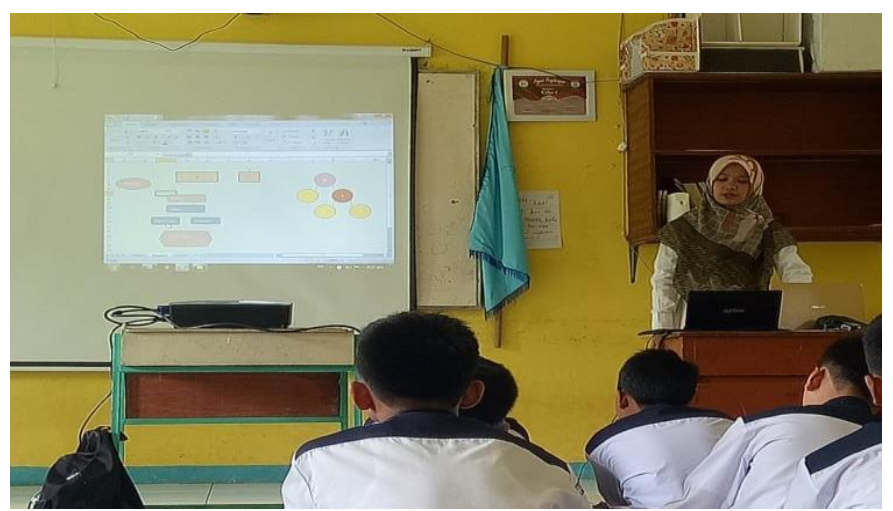

Gambar 1. Pemberian materi menggunakan VBA Excel

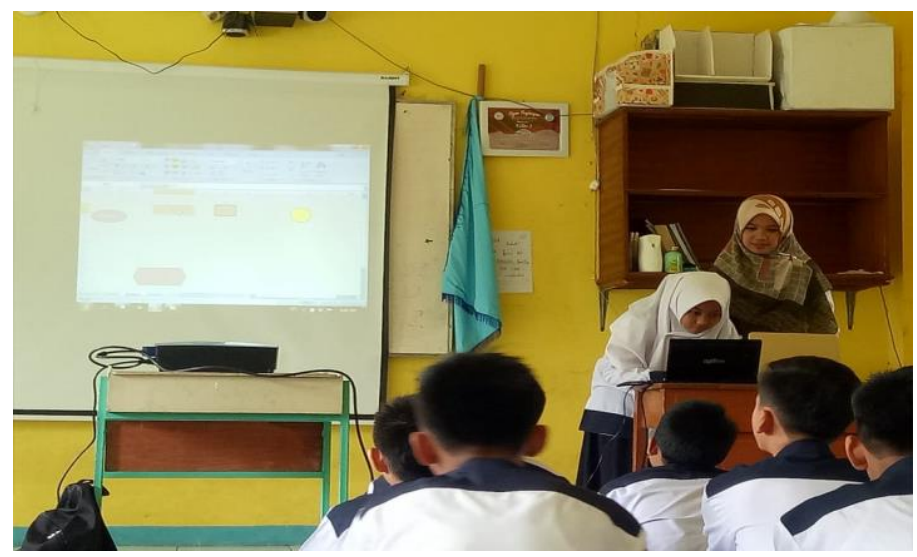

Gambar. 2 Antusias siswa ketika mencoba VBA Excel

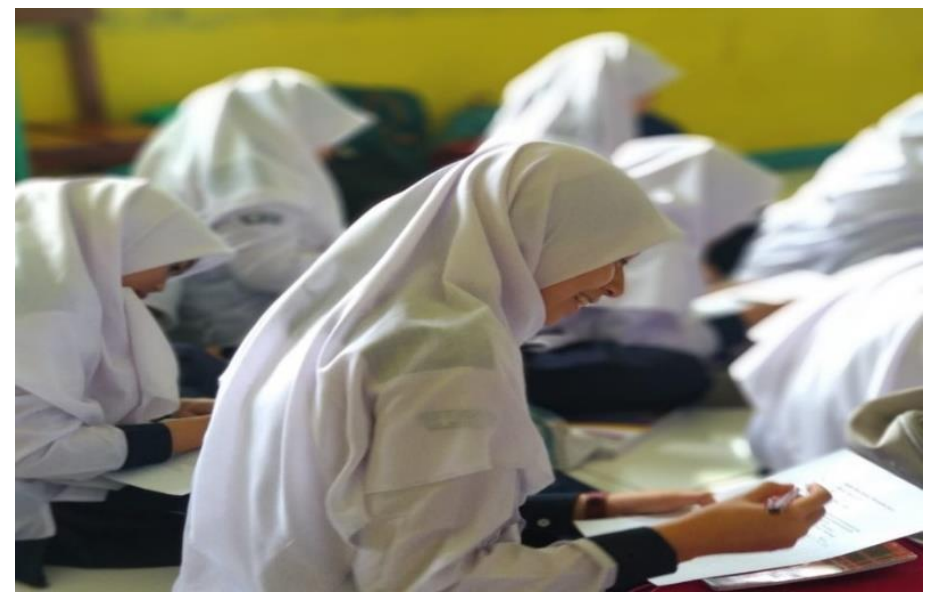

Gambar. 3 Mengisi angket minat belajar

Kegiatan pada Gambar. 1 adalah kegiatan peneliti ketika menjelaskan materi KPK dan FPB berbantuan VBA Excel. Kegiatan pada Gambar. 2 adalah memperlihatkan subjek ketika antusias mencoba materi yang telah dijelaskan peneliti menggunakan VBA Excel, ada beberapa subjek secara bergantian yang 
tertarik mencoba materi menggunakan VBA Excel ini. Kegiatan pada Gambar. 3 adalah pengisian angket yang dilakukan oleh 22 orang subjek sampel dimana angket berisi pernyataan yang terdiri dari 20 pernyataan diantaranya 10 pernyataan positif dan 10 pernyataan negatif, untuk mengetahui sejauh mana minat siswa terhadap meteri yang menggunakan aplikasi VBA Excel.

Kemudian hasil data yang diperoleh dari skala minat belajar tersebut dapat dilihat dari tabel berikut:

Tabel. 4

Persentase skala sikap minat belajar

\begin{tabular}{clccccc} 
No & \multicolumn{1}{c}{ Indikator } & $\begin{array}{l}\text { Banyak } \\
\text { Pernyataan }\end{array}$ & $\begin{array}{c}\text { Total } \\
\text { Skor }\end{array}$ & Mean & Persentase & Keterangan \\
\hline 1 & Perasaan Senang & 5 & 376 & 75 & 85.45 & BAIK \\
\hline 2 & Ketertarikan Siswa & 5 & 366 & 73 & 83.18 & BAIK \\
\hline 3 & Keterlibatan Siswa & 3 & 219 & 73 & 82.95 & BAIK \\
\hline 4 & $\begin{array}{l}\text { Rajin dan semangat } \\
\text { mengerjakan tugas }\end{array}$ & 4 & 278 & 70 & 78.98 & BAIK \\
\hline 5 & $\begin{array}{l}\text { Tekun dan disiplin } \\
\text { dalam belajar }\end{array}$ & 3 & 209 & 70 & 79.17 & BAIK \\
\hline & Total & 20 & 1448 & 72.2 & 82.27 & BAIK \\
\hline
\end{tabular}

Dari tabel 4 persentase skala sikap minat belajar siswa berdasarkan indikator perasaan senang terdapat $85.45 \%$, pada indikator ketertarikan siswa tyerdapat $83.18 \%$, pada indikator keterlibatan siswa terdapat $82.95 \%$, pada indikator rajin dan semangat mengerjakan tugas terdapat $78.98 \%$ dan pada indikator tekun dan disiplin dalam belajar terdapat $79.19 \%$. Berdasarkan pencapaian nilai menurut Sudijono (Rojabiyah \& Setiawan, 2015), menunjukan bahwa persentase rata-rata pada kelima indikator adalah baik, sehingga dalam penelitian ini menunjukan bahwa minat belajar matematika pada materi KPK dan FPB dengan berbantuan VBA Excel adalah baik.

Berikut deskriptif visual data minat belajar siswa

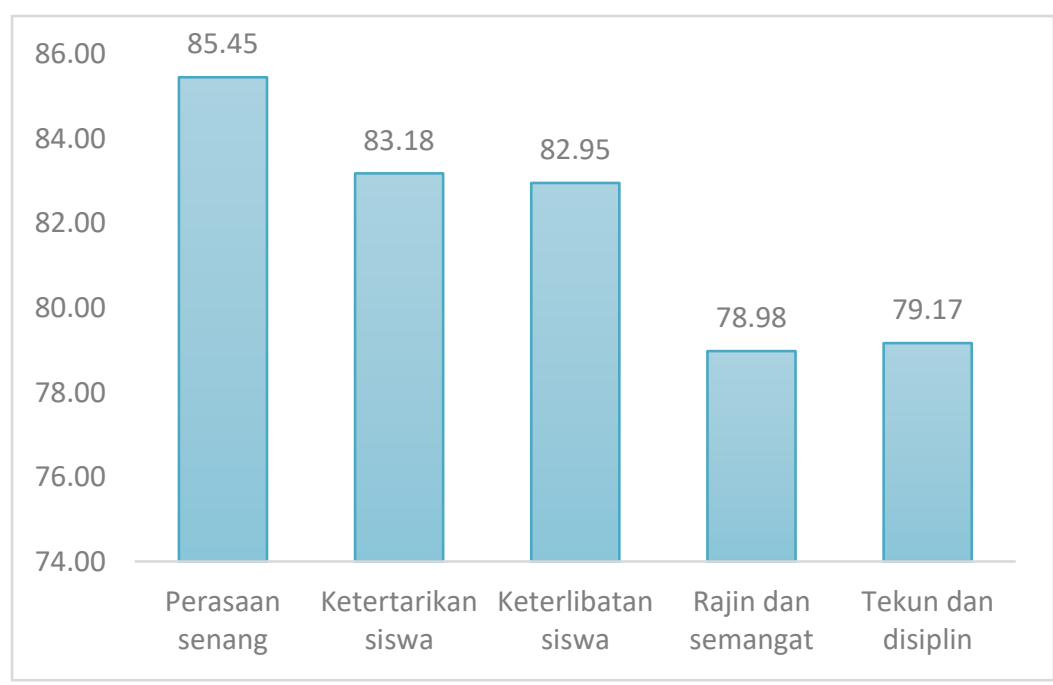

Gambar. 4 Diagram persentase minat belajar 
Dari gambar 4 diagram indikator pada minat belajar siswa untuk indikator perasaan senang memperoleh persentase tertinggi yaitu $85.45 \%$, pada indikator ketertarikan siswa memperoleh persentase $83.18 \%$, sedangkan pada indikator keterlibatan mendapatkan $82.95 \%$, sedangkan pada indikator rajin dan semangat dalam mengerjakan tugas hanya mendapatkan $78.98 \%$ tetapi meskipun persentasenya paling sedikit pada indikator ini masih tetap minat belajarnya adalah baik, dan yang terakhir pada indikator tekun dan disiplin dalam belajar mendapatkan persentase sebesar $79.17 \%$

Dari data diatas dapat dilihat pada kelima indikator tersebut rata-rata yang diperoleh siswa SMP kelas VII pada pembelajaran matematika materi KPK dan FPB menggunakan aplikasi VBA Excel memperoleh respon yang baik sehingg mendorong minat belajar yang baik pula.

\section{KESIMPULAN}

Berdasarkan hasil dan pembahasan terhadap analisis minat belajar siswa dalam pembelajaran matematika kelas VII pada materi KPK dan FPB dengan berbantuan aplikasi VBA Excel, persentase yang dihasilkan secara keseluruhan dari kelima indikator adalah $82.27 \%$ yang artinya adalah baik, sehingga analisis yang dilakukan menunjukan bahwa minat belajar siswa dalam pembelajaran matematika pada materi KPK dan FPB dengan berbantuan VBA Excel adalah baik

\section{DAFTAR PUSTAKA}

Adni, D. N., Puji, N., \& Rohaeti, E. E. (2018). Analisis Kemampuan Koneksi Matematis Siswa SMP Ditinjau Dari Self Efficacy Siswa. 1(5), 957-964.

Chotimah, S., Sari, I. P., \& Zhanty, L. S. (2019). Analisis Kemampuan Pemecahan Masalah Matematik Siswa SMP Pada Materi Kubus dan Balok. 6(2), 1-4.

Flora Siagian, R. E. (2015). Pengaruh Minat dan Kebiasaan Belajar Siswa terhadap Prestasi Belajar Matematika. Formatif: Jurnal Ilmiah Pendidikan MIPA, 2(2), 122-131. https://doi.org/10.30998/formatif.v2i2.93

Gusniwati, M. (2015). Pengaruh Kecerdasan Emosional dan Minat Belajar terhadap Penguasaan Konsep Matematika Siswa SMAN di Kecamatan Kebon Jeruk. Formatif: Jurnal Ilmiah Pendidikan MIPA, 5(1), 26-41. https://doi.org/10.30998/formatif.v5i1.165

Hendriana, H., Rohaeti, E. E., \& Sumarmo, U. (2017). Hard Skills dan Soft Skills Matematik Siswa (N. . Atif, ed.). Bandung: Refika Aditama.

Lestari, I. (2015). Pengaruh Waktu Belajar dan Minat Belajar terhadap Hasil Belajar Matematika. Formatif: Jurnal Ilmiah Pendidikan MIPA, 3(2), 115-125. https://doi.org/10.30998/formatif.v3i2.118

Nurfauziah, P., \& Fitriani, N. (2019). Gender dan Resiliensi Matematis Siswa SMP dalam Pembelajaran Scientific Berbantuan VBA Excel. Symmetry, 4, 28-37. 
Rohaeti, E. E., \& Purwasih, R. (2018). Meningkatkan Kemampuan Komunikasi Matematik dan Kemandirian Belajar Siswa SMP melalui Pendekatan Realistic Mathematics Education 1. 9(1), $113-123$.

Rohaeti E.E, Bernard M, Chotimah, S. (2018). Media Pembelajaran Matematika Berbasis Information Communication and Technology dengan VBA Microsoft Excel (M. . Wildani, ed.). Bandung: Refika Aditama.

Rojabiyah, A. B., \& Setiawan, W. (2015). Analisis Minat Belajar Siswa MTs Kelas VII Dalam Pembelajaran Materi Aljabar Berdasarkan Gender. 01(02), 458-464. 